\title{
Tonsillectomy as a Prevention Strategy in the Light of Increasing Incidence of Oropharyngeal Cancer - a Research of Current Literature
}

\author{
ACHIM M. FRANZEN $^{1}$ and JOCHEN P. WINDFUHR ${ }^{2}$ \\ ${ }^{1}$ Department of Oto-Rhino-Laryngology, Medical University Brandenburg, \\ Campus Ruppiner-Kliniken, Neuruppin, Germany; \\ ${ }^{2}$ Department of Oto-Rhino-Laryngology, Klinikum Maria Hilf, Mönchengladbach, Germany
}

\begin{abstract}
Background/Aim: While in many Western countries the number of tonsillectomies decreases significantly, there is an increasing incidence of oropharyngeal carcinomas. For, obviously, removal of the tonsils will reduce individual risk for tonsil cancer, the question of tonsillectomy as a prevention strategy is suggested. This study focused on this question by carrying out a literature research. Materials and Methods: A literature research was performed (www.pubmed.gov; Search words: tonsillectomy, oropharyngeal cancer, tonsil cancer, prevention) without applying additional filters. Results: Out of the 16 identified studies, three population-based studies were evaluated. Individual incidence of tonsil cancer is significantly lower after removal of tonsils; however, risk elimination by tonsillectomy has not been proven. One of the studies revealed increasing numbers of base of the tongue cancer after previous tonsillectomy. Conclusion: The increase in oropharynx carcinomas can currently be attributed not to the decreasing tonsillectomy rates, but to the increase in HPV infections. A previous tonsillectomy reduces the individual risk of developing tonsil carcer. Tonsillectomy as prevention for oropharyngeal cancer cannot be recommended and may even be a disadvantage concerning base of the tongue cancers.
\end{abstract}

This article is freely accessible online.

Correspondence to: Dr. med. Achim M. Franzen, Medizinische Hochschule Brandenburg, Klinik für HNO-Krankheiten und plastische Operationen, Campus Ruppiner-Kliniken $\mathrm{GmbH}$, Fehrbelliner Straße 38, 16816 Neuruppin, Germany. Tel: +33 913947710, Fax: +33913947709, e-mail: a.franzen@ruppinerkliniken.de

Key Words: Tonsillectomy, oropharyngeal cancer, tonsil cancer, human papilloma virus infection, prevention, review.
Tonsillectomy (TE) is one of the most common interventions in the field of otorhinolaryngology, but the frequency of the procedure is declining rapidly in many Western countries. This development, which has been well documented in many European countries and in North America in the last five decades, can also be observed in Germany $(1,2)$. The incidence of oropharyngeal cancer (OCA), especially tonsil cancer (TCA) has been increasing in the last decades $(3,4)$; the stationary case numbers are also steadily increasing in Germany for both entities (Figure 1). Since a carcinoma manifestation is not possible on an organ that no longer exists, the question arises whether TE is justified as a "carcinoma prophylaxis" to avoid TCA/OCA. The aim of the present study was to answer this question based on literature search.

\section{Materials and Methods}

A literature search in Pubmed (5) was carried out using the search words "tonsillectomy, oropharyngeal cancer, tonsil cancer and prevention" without the application of further filters. Studies unrelated to the subject or opinions were excluded. The procedure is shown in Figure 2 and followed the validated PRISMA recommendation (6). Studies not published in German or English were also excluded.

\section{Results}

Out of 16 identified studies, three were related to the aim of this study (Figure 2; Table I). All studies were populationbased; two cases included historical patient material $(7,8)$, and one case (9) with more recent data. All studies support the presumption that a previous TE reduces the individual risk of developing TCA; none of the studies, however, was able to demonstrate a risk elimination of TCA by TE. In one study, TE increased the risk of developing a base of the tongue cancer (BOTCA), especially in cases with a human 


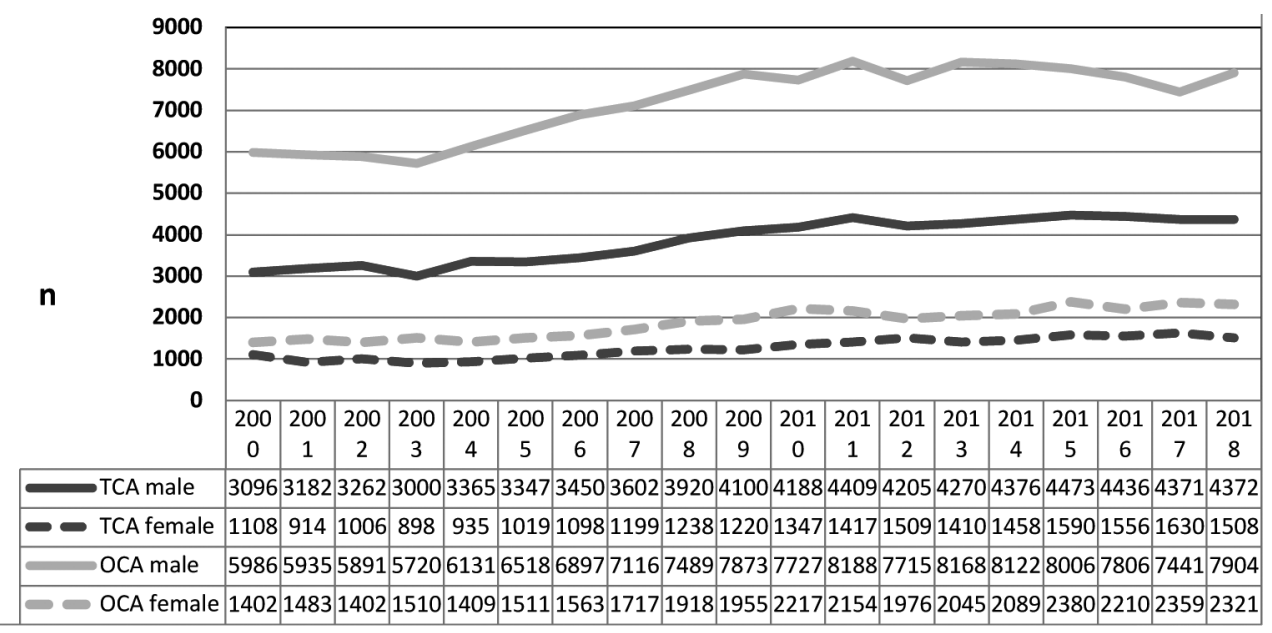

Figure 1. Numbers of inpatients with tonsil cancer (TCA) and oropharyngeal cancer (OCA) in Germany.

papilloma virus (HPV)-positive status and a TE performed at a young age. The date of carcinoma diagnosis was proved to be decisive in one of the studies, and in another, the time of TE (Table I).

\section{Discussion}

In view of the increase in (HPV-positive) OCA, especially TCA, the question arises as to whether this can be explained in the context of the decreasing number of tonsillectomies internationally (10). This study aimed to clarify the potential of TE to prevent carcinogenesis in the tonsils or even in the entire oropharynx $(3,11)$. According to our research, only three population-based studies (7-9) with a focus on this subject have been published (Table I).

All studies (7-9) show that the individual probability of developing TCA is reduced after a TE (Table I). Fakhry et al. (7) also confirmed this, but showed that a high proportion of diagnostic tonsillectomies had been carried out in the patients included in their study. The collective was then stratified by age and a significant risk reduction for OCA/TCA was demonstrated for patients younger than 60 years of age (not significant for the BOTCA). In contrast, for patients $>60$ years of age with a BOTCA, a significant increase in risk was found by TE (not significant when diagnosing OCA/TCA). Regarding the survival rate, patients benefited from a TE carried out within one year before OCA/TCA compared to patients who had an earlier TE or not at all.

According to the results of Zevallos et al. (9), a TE reduced the risk of a TCA to one-fifth but increased the risk of BOTCA by two times and had no influence on the development of other head and neck carcinomas (HNCA). At the time of TE, a distinction was made between children
( $<13$ years) and teenagers/adults ( $>13$ years). In addition, various risk factors were identified (high number of sexual partners, $>10$ pack-years, HPV status). The effect on BOTCA and TCA was even intensified by a TE carried out in childhood or with a positive HPV status, for which there are no scientifically plausible explanations.

Chaturvedi et al. (8) used the data of 225,718 patients with a history of TE, most of whom were under 20 years of age (median: 16 years). Out of 144 patients with HNCA, the rate of those with malignancies in the oropharynx, tonsils and head-neck within a year after TE equally increased. This finding was attributed to the diagnostic importance of TE. Subsequently, TE had an impact only on risk reduction for acquiring TCA, not on the other entities.

Almost at the same time with these three studies, Gayar reported a significant increase in OCA in the US between 1973 and 2009, especially among younger patients (12). The figures of the Federal Statistical Office could not prove such a development between 2000 and 2018: the number of cases with both TCA and OCA increased only in the group of over 65 years of age (Table II).

The lack of risk reduction for other HNCA indicates that biological or immunological effects of TE on the pathogenesis of carcinomas do not appear to exist (11). The effect of TE on TCA and OCA mainly concerns HPV-positive carcinomas; carcinomas of the mucosa and scar tissue after a TE were usually associated with tobacco/alcohol exposition. The accumulation of HP viruses in lymphatic tissue is discussed as causative for carcinoma development (9).

Statistically, the studies analyzed in our research excluded a monocausal rise of the incidence of TCA and OCA due to the decline in TE. The authors consider the increase in HPV infections as the main reason (7-9). Fakhry et al. (7) 


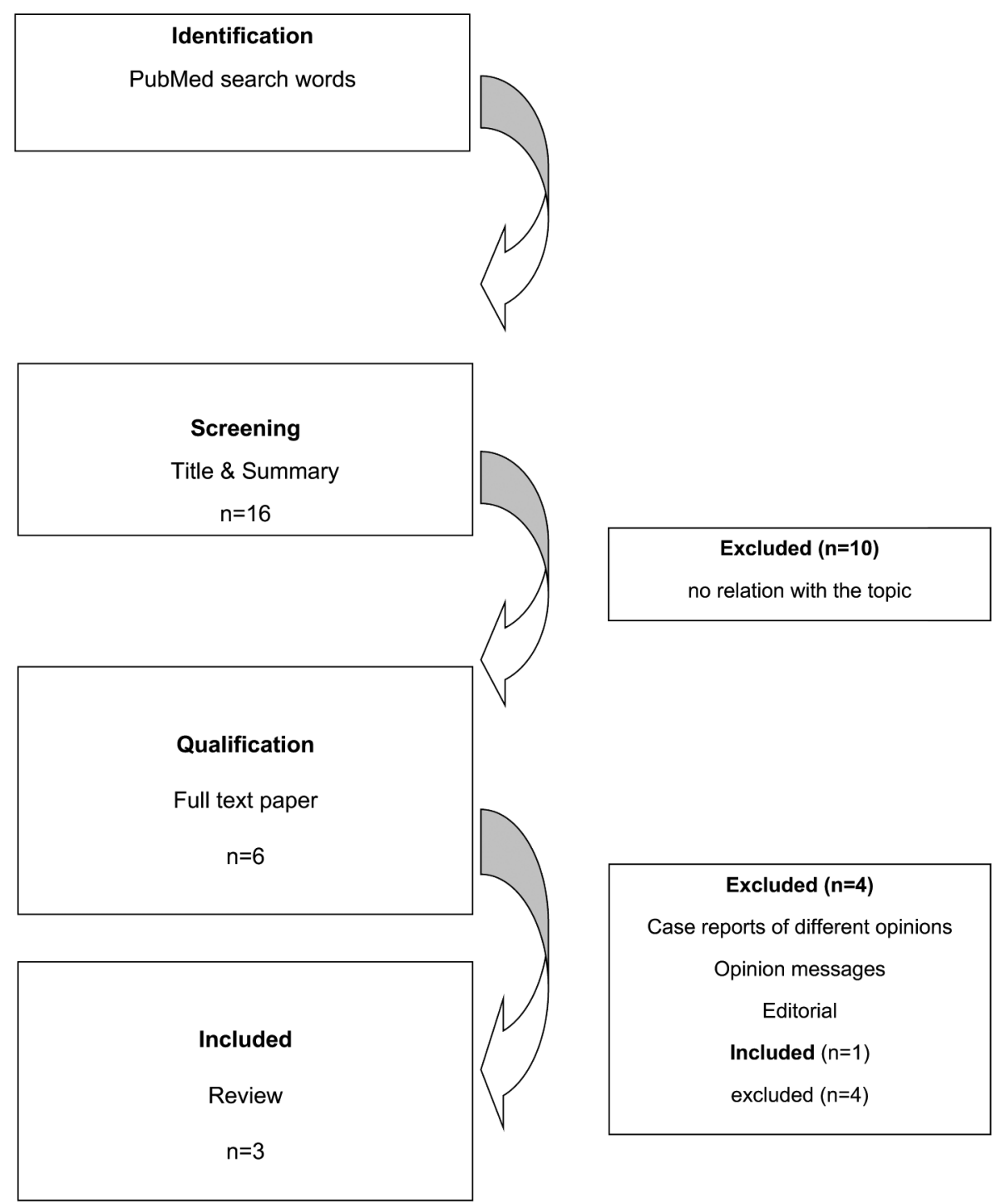

Figure 2. PRISMA-Flow diagram.

determined that most patients were younger than 20 years of age at the time of TE and older than 59 years of age at the time of carcinoma diagnosis. They compared the $1.1 \%$ annual decline in TE with the $6.0 \%$ annual increase in OCA, which excludes monocausality. In addition, of the total collective of patients with a carcinoma $1 \%$ had the TE more than a year ago and $3.4 \%$ less than a year ago, while $95.6 \%$ had an earlier TE or not at all.

In Germany, the strongest relative increase in OCA was found in females (66\% vs. 32\%; Figure 1), despite significantly higher TE frequency than in males. This is an important argument against a monocausal relationship between the frequency of TE and the incidence of OCA/TCA (2).
Since causal relationships cannot be formulated, prophylactic TE is rejected by all authors. Another important reason why TE is not justified is the risk of surgery. Calculations by Fakhry et al. (7) showed that a prophylactic TE would reduce the incidence of TCA from 3.64 to 1.52 annual cases/100,000. The gain would not be related to postoperative morbidity and mortality risk $(13,14)$. In addition, a prophylactic TE accepts an unknown number of patients who would never have had carcinoma but would have expected potential effects on the immune system and development of secondary diseases; apart from the associated costs for the payers (15).

On the other hand, in at-risk patients, trying to prevent the development of an OCA by a TE seems desirable. The 
Table I. Epidemiologic studies.

\begin{tabular}{|c|c|c|c|c|c|c|}
\hline Author & Country & TE (n) & Carcinoma (n) & Period & TCA Risc-reduction & Results \\
\hline Chaturvedi (4) & Sweden & 225.718 & $144 \mathrm{KHCA}$ & 1970-2009 & $69-83 \%$ & $\begin{array}{l}\text { - Significant risk reduction for TCA } \\
\text { - No risk reduction for OCA/HNCA } \\
\text { - crucial HPV status not affected by TE } \\
\text { - Identification of at-risk patients not possible } \\
\text { - HPV vaccination and detection/treatment } \\
\text { of precancerous lesions is essential } \\
\text { - prophylactic TE is not recommended }\end{array}$ \\
\hline Fakhry (7) & Danmark & 90.755 & $2788 \mathrm{TCA}$ & $1977-2012$ & $\begin{array}{c}60 \%(\text { all }) \\
85 \%(<60 \text { years })\end{array}$ & $\begin{array}{l}\text { - Significant risk reduction for }<60 \text { years } \\
\text { with TCA/OCA } \\
\text { - Significant risk increase for }>60 \text { years } \\
\text { with BOTCA } \\
\text { - Prophylactic TE without biomarkers } \\
\text { with predictive value is not recommended }\end{array}$ \\
\hline Zevallos (22) & US & 544 & $\begin{array}{c}198 \text { TCA } \\
\text { of } 361 \text { OCA }\end{array}$ & 2002-2006 & $78 \%$ & $\begin{array}{l}\text { - TE increases BOTCA risk; TE }<13 \text {. LJ } \\
\text { and HPV-positive (!) enhance this effect } \\
\text { - TCA risk does not depend on time of TE } \\
\text { - The effect of TE is more detectable } \\
\text { in HPV-positive status } \\
\text { - Prophylactic TE is not recommended }\end{array}$ \\
\hline
\end{tabular}

TE: Tonsillectomy; TCA: tonsil cancer; OCA: oropharyngeal cancer; HNCA: head and neck cancer; BOTCA: base of the tongue cancer; HPV: Human papilloma virus.

Table II. Number of inpatients per 100,000 inhabitants.

$20002001200220032004200520062007200820092010201120122013 \quad 20142015201620172018$

\begin{tabular}{lrrrrrrrrrrrrrrrrrrrr}
\hline $\begin{array}{l}\text { Tonsil cancer } \\
<45 \text { years }\end{array}$ & 1 & 1 & 1 & 1 & 1 & 1 & 1 & 1 & 1 & 1 & 1 & 1 & 1 & 1 & 0 & 0 & 0 & 0 & 0 \\
$<65$ years & 13 & 12 & 13 & 12 & 13 & 13 & 14 & 14 & 15 & 15 & 15 & 16 & 15 & 15 & 15 & 15 & 14 & 14 & 13 \\
$\geq 65$ years & 8 & 8 & 8 & 7 & 8 & 8 & 8 & 9 & 10 & 10 & 11 & 12 & 12 & 12 & 12 & 13 & 14 & 14 & 14 \\
& & & & & & & & & & & & & & & & & \\
$\begin{array}{l}\text { Oropharyngeal cancer } \\
<45 \text { years }\end{array}$ & 2 & 1 & 1 & 1 & 1 & 1 & 1 & 1 & 1 & 1 & 1 & 1 & 1 & 1 & 1 & 1 & 1 & 1 & 0 \\
$<65$ years & 24 & 24 & 23 & 23 & 24 & 25 & 26 & 26 & 28 & 28 & 28 & 28 & 26 & 26 & 27 & 26 & 23 & 23 & 24 \\
$\geq 65$ years & 13 & 12 & 12 & 12 & 13 & 14 & 15 & 16 & 17 & 18 & 19 & 20 & 20 & 21 & 21 & 23 & 23 & 22 & 24 \\
\hline
\end{tabular}

problem is the lack of biomarkers to identify at-risk patients (7). Only if precancerous lesions, similar to cervical cancer, could be detected by appropriate risk stratification (e.g. biomarkers, imaging, cytology) a TE would most likely prevent the manifestation of a TCA (7). With HPV positiveness in saliva of $1 \%$ of the American general population between 14 and 69 years of age, this marker would affect 2.13 million people, only a fraction of whom will develop a TCA (16). Since it is usually years between the detection of HPV seroposivity and the development of an OCA, intensive clinical monitoring is currently appropriate in HPV-positive patients (16). So far, only the number of oral sex partners has been identified as a risk factor (17). Apart from the uncertainty of anamnestic data,
$80 \%$ of OCA occurs in non-promiscuous patients. Moreover, reduction in other OCA, which amounts to $30-40 \%$, could not be demonstrated after TE. This finding is also inconsistent with TE being prophylactic, too. Finally, Zevallos was able to show that BOTCA is even more common after TE $(7,9)$.

Instead of the prophylactic TE, all studies recommend primary prevention by vaccination (7-9). This has been the case with the vaccination for cervix uteri carcinoma. However, the results of this vaccination can only be expected in decades, provided that vaccination rates are sufficient. In Germany, vaccination is now paid by health insurances and is recommended for adolescents of both sexes from the age of 13. In other countries, acceptance of the vaccine is rather 
sobering; in $2013,14 \%$ of male adolescents in the US were vaccinated (vaccination was introduced in 2009). In Europe, the proportion of vaccinated individuals reaches an average of 17\%, whereas in England and Portugal around 80\% (11).

\section{Conclusion}

Three studies were identified to report on the decrease in TE cases and the increasing incidence of OCA/TCA. There is no monocausal link between the two phenomena. HPV prevalence is primarily suspected as causal by all authors. HPV status and age in TE as well as in cancer diagnosis also play a role. The final assessment of the subject requires prospective studies.

TE reduces, but does not eliminate, individual TCA risk. Biomarkers and typing characteristics of precancerous conditions of OCA/TCA are currently not available for the identification of at-risk patients. "Prophylactic TE" cannot be scientifically justified.

\section{Conflicts of Interest}

The Authors report no conflicts of interest in relation to this study.

\section{Authors' Contributions}

The Authors have contributed in equal shares.

\section{References}

1 Windfuhr JP: Tonsillektomie: Offizielle zahlen und trends in Deutschland. Laryngorhinootologie 95: S88-S109, 2016. PMID: 27128406. DOI: $10.1055 / \mathrm{s}-0041-109594$

2 Windfuhr JP and Chen YS: Do changing trends in tonsil surgery affect hemorrhage rates? A longitudinal study covering 1,452,637 procedures. Eur Arch Otorhinolaryngol 276: 2585-2593, 2019. PMID: 31256244. DOI: 10.1007/s00405-019-05532-3

3 Chaturvedi AK: Tonsillectomy and risk of oropharyngeal cancer: implications for research and prevention. Cancer Prev Res (Phila) 8: 577-579, 2015. PMID: 25896235. DOI: 10.1158/19406207.CAPR-15-0135

4 Wienecke A and Kraywinkel K: Tabakassoziierte Krebserkrankungen in Deutschland - Entwicklung der Inzidenz und Mortalitat seit 1995. Bundesgesundheitsblatt Gesundheitsforschung Gesundheitsschutz 61: 1399-1406, 2018.

6 Baugh RF, Archer SM, Mitchell RB, Rosenfeld RM, Amin R, Burns JJ, Darrow DH, Giordano T, Litma RS, Kasey KL, Mannix ME, Schwartz RH, Stzen G, Wald ER, Wall E Sandberg $\mathrm{G}$ and Patel MM: Clinical practice guideline: tonsillectomy in children. Otolaryngol Head Neck Surg 144: S1-30, 2011. PMID: 21493257. DOI: $10.1177 / 0194599810389949$
5 Pubmed. Available at: https://Pubmed.ncbi.nlm.nih.gov [Last accessed on January 19, 2020]

7 Fakhry C, Andersen KK, Christensen J, Agrawal N and Eisele DW: The impact of tonsillectomy upon the risk of oropharyngeal carcinoma diagnosis and prognosis in the Danish Cancer Registry. Cancer Prev Res (Phila) 8: 583-589, 2015. PMID: 25896236. DOI: 10.1158/1940-6207.CAPR-15-0101

8 Chaturvedi AK, Song H, Rosenberg PS, Ramqvist T, Anderson WF, Munck-Wikland E, Ye W and Dalianis T: Tonsillectomy and incidence of oropharyngeal cancers. Cancer Epidemiol Biomarkers Prev 25: 944-950, 2016. PMID: 26976856. DOI: 10.1158/1055-9965.EPI-15-0907

9 Zevallos JP, Mazul AL, Rodriguez N, Weissler MC, Brennan P, Anantharaman D and Abedi-Ardekani B: Previous tonsillectomy modifies odds of tonsil and base of tongue cancer. Br J Cancer 114: 832-838, 2016. PMID: 26977858. DOI: 10.1038/bjc.2016.63

10 Phillips J and Hilger A: Surgery: are we performing enough tonsillectomies? Nat Rev Clin Oncol 6: 439-440, 2009. PMID: 19644532. DOI: $10.1038 /$ nrclinonc.2009.105

11 Misiukiewicz K and Posner M: Role of prophylactic bilateral tonsillectomy as a cancer preventive strategy. Cancer Prev Res (Phila) 8: 580-582, 2015. PMID: 26100523. DOI: 10.1158/19406207.CAPR-15-0153

12 Gayar O, Ruterbusch J, Elshaikh M, Cote M, Ghanem T, Hall F and Siddiqui F: Oropharyngeal carcinoma in young adults: An alarming national trend. Otolaryngol Head Neck Surg 150: 594 601, 2014. PMID: 24452304. DOI: 10.1177/0194599813519738

13 Windfuhr JP, Schloendorff G, Baburi D and Kremer B: Lethal outcome of post-tonsillectomy hemorrhage. Eur Arch Otorhinolaryngol 265: 1527-1534, 2008. PMID: 18506467. DOI: 10.1007/s00405-008-0699-4

14 Windfuhr JP, Schloendorff G, Sesterhenn AM, Prescher A and Kremer B: A devastating outcome after adenoidectomy and tonsillectomy: ideas for improved prevention and management. Otolaryngol Head Neck Surg 140: 191-196, 2009. PMID: 19201287. DOI: $10.1016 /$ j.otohns.2008.11.012

15 Byars SG, Stearns SC and Boomsma JJ: Association of longterm risk of respiratory, allergic, and infectious diseases with removal of adenoids and tonsils in childhood. JAMA Otolaryngol Head Neck Surg 144: 594-603, 2018. PMID: 29879264. DOI: 10.1001/jamaoto.2018.0614

16 D'souza G, Gross ND, Pai SI, Haddad R, Andersen KS, Rajan S, Gerber J, Gillison ML and Posner MR: Oral human papillomavirus (HPV) infection in HPV-positive patients with oropharyngeal cancer and their partners. J Clin Oncol 32: 24082415, 2014. PMID: 24778397. DOI: 10.1200/JCO.2014.55.1341

17 D'souza G and Dempsey A: The role of HPV in head and neck cancer and review of the HPV vaccine. Prev Med 53: S5-S11, 2011. PMID: 21962471. 10.1016/j.ypmed.2011.08.001

Received December 29, 2020 Revised January 14, 2021 Accepted January 21, 2021 